\title{
Increased fucosyl glycoconjugate by Mycoplasma hyopneumoniae enhances adherences of Pasteurella multocida type $A$ in the ciliated epithelial cells of the respiratory tract
}

\author{
Changhoon Park, Jiwoon Jeong ${ }^{\dagger}$, Ikjae Kang, Kyuhyung Choi, Su-Jin Park and Chanhee Chae*
}

\begin{abstract}
Background: The objective of this study was to elucidate the pathogenic mechanisms of how Mycoplasma hyopneumoniae enhances secondary Pasteurella multocida type A infection which leads to porcine enzootic pneumonia in infected pigs. Sixteen pigs were experimentally infected with M. hyopneumoniae and then euthanized at 7, 14, 21 and 28 days post inoculation. In situ hybridization for M. hyopneumoniae DNA and Ulex europaeus agglutinin-I (UEA-I) lectin histochemistry for fucosyl glycoconjugate, was performed in serial lung sections to determine alteration of fucosyl glycoconjugate in M. hyopneumoniae-infected bronchial and bronchiolar epithelium. Bacterial overlay assay was performed to determine the affinity of $P$. multocida type A with L-fucose.

Results: The luminal surface of bronchial and bronchiolar epithelial cells that were stained with UEA-I always showed hybridization signals for M. hyopneumoniae but it was negative in the unaffected parts of the lung from M. hyopneumoniae-infected pigs and in lung from negative control pigs. Colocalization of M. hyopneumoniae and UEA-I was especially prominent in the luminal surface of bronchial and bronchiolar epithelial cells in serial section of lung. The mean number of M. hyopneumoniae-positive cells correlated with the mean number of UEA-I-positive cells in lungs from infected pigs throughout the experiment. All eight $P$. multocida type A isolates from naturally occurring enzootic pneumonia, bound strongly at levels of $2 \mu \mathrm{g}$ and $5 \mu \mathrm{g}$ of L-fucose.
\end{abstract}

Conclusions: The results of the present study demonstrate that M. hyopneumoniae increases the L-fucose composition to enhance adherence of $P$. multocida type A to the bronchial and bronchiolar epithelial cells.

Keywords: Co-infection, Enzootic pneumonia, Mycoplasma hyopneumoniae, Pasteurella multocida

\section{Background}

Mycoplasmal pneumonia, caused by Mycoplasma hyopneumoniae, is characterized by dry cough, retardation of growth, poor feeding efficiency, and susceptibility of pigs to secondary bacterial infection, especially Pasteurella multocida type A $[1,2]$. Although P. multocida type A is the most common secondary pathogen in $M$.

\footnotetext{
* Correspondence: swine@snu.ac.kr

${ }^{\dagger}$ Equal contributors

College of Veterinary Medicine, Seoul National University, 1

Gwanak-roGwanak-gu, Seoul 151-742, Republic of Korea
}

hyopneumoniae-infected pigs, experimental infection of P. multocida type A alone is not sufficient in inducing pneumonia and generally is asymptomatic in pigs [3, 4]. In contrast, infection by this organism followed by primary infection with $M$. hyopneumoniae exacerbates mycoplasmal pneumonia which can lead to porcine enzootic pneumonia in pigs $[2,4,5]$. The damaged ciliated epithelium and suppressed immunity by the M. hyopneumoniae infection are the main factors underlying the secondary $P$. multocida type A infection $[1,2]$. Nonetheless, mechanisms of enhanced secondary $P$. 
multocida type A infection by M. hyopneumoniae have not been elucidated.

Bacterial adherence is an important initial step in the infection process that involves specific interaction between bacterial adhesins and host receptors [6, 7]. A variety of mucosal epithelial cell glycoconjugates and glycolipids act as receptors for respiratory bacterial pathogens $[8,9]$. Therefore, altered composition of glycoconjugates as the result of mycoplasmal infection may be one factor that predisposes pigs to enhance secondary $P$. multocida type A infection in the lung. It has been reported that infection with $M$. hyopneumoniae enhances Ulex europaeus agglutinin-I (UEA-I), which has affinity of glycoconjugates for L-fucose residues, in ciliated epithelium of the respiratory tract in infected pigs [10]. These results suggest that $M$. hyopneumoniae infection can alter the composition of glycoconjugates to render the lungs susceptible to P. multocida type A infection.

In order to better understand the pathogenic mechanisms of how $M$. hyopneumoniae enhances the secondary $P$. multocida type A infection, first, the composition of fucosyl glycoconjugates in $M$. hyopneumoniae-infected bronchial and bronchiolar epithelium was examined, using in situ hybridization for M. hyopneumoniae DNA and UEA-I lectin histochemistry for fucosyl glycoconjugates. Second, the affinity of $P$. multocida type A for L-fucose was assessed using bacterial overlay assay.

\section{Methods}

\section{Experimental design}

A total of 32 colostrum-fed, cross-bred, conventional piglets were purchased at 14 days of age from a porcine reproductive and respiratory syndrome virus (PRRSV)and M. hyopneumoniae-free commercial farm based on serological testing of the breeding herd, and long term clinical and slaughter history. All piglets were negative for porcine circovirus type 2 (Synbiotics, Lyon, France), and PRRSV, swine influenza virus and M. hyopneumoniae (IDEXX Laboratories Inc., Westbrook, ME) according to routine serological testing.

Pigs aged 14 days were randomly allocated into infected or control groups ( $n=10$ per group) using the random number generation function in Excel (Microsoft Corporation, Redmond, WA). At 21 days of age (0 days post inoculation, dpi), 16 pigs in the infected group were intratracheally administered a $10-\mathrm{ml}$ dose of a lung homogenate of M. hyopneumoniae strain SNU98703 (1:100 dilution in Friis medium) at a final concentration of $10^{4}-10^{5}$ color-changing units $(\mathrm{CCU}) / \mathrm{ml}$, as previously described [11]. No bacterial and viral pathogens were isolated from a lung homogenate of $M$. hyopneumoniae strain SNU98703. Sixteen control pigs were exposed in the same manner to uninfected Friis medium. Four pigs from each group were sedated by an intravenous injection of sodium pentobarbital and then euthanized by electrocution at 7 , 14,21 , and 28 dpi as previously described [12]. Tissues were collected from each pig at necropsy. All of the methods were previously approved by the Seoul National University, Institutional Animal Care and Use, and Ethics Committee (SNU-140043-11B, date of approval 10 January 2014).

\section{Preparation of labeled probe}

A 520-base-pair DNA fragment was used as a probe. The forward and reverse primers were 5'-GTGTATC AAAATTGCCAATC-3' (nucleotides 851 to 870 ) and 5'TCCCATAACCTTGTCTTCAG-3' (nucleotides 1351 to 1370), respectively [13]. PCR was performed as previously described [13]. The PCR products were purified with Wizard PCR Preps (Promega Biotech, Madison, WI). The purified PCR products were labeled by random priming with digoxigenin-dUTP using a commercial kit (Boehringer Mannheim, Indianapolis, IN).

\section{In situ hybridization}

Tissues were routinely fixed for $24 \mathrm{~h}$ in $10 \%$ neutral buffered formalin. After fixation, the tissues from each pig were dehydrated through a graded series of alcohol solutions and a xylene step and embedded in paraffin wax. Four serial sections $(4 \mu \mathrm{m})$ were then prepared from each tissue, two being further processed for in situ hybridization (ISH) using a M. hyopneumoniae probe with and without DNase A treatment, one for lectin histochemistry using an UEA-I lectin, and one for haematoxylin and eosin (HE) staining. ISH was performed as previously described [14]. The lung tissues from pigs experimentally infected with $M$. hyopneumoiniae were used as positive controls for ISH [15].

\section{Lectin histochemistry}

Sections were deparaffinized in xylene, hydrated through a graded series of alcohols to straight distilled water. Endogenous alkaline phosphatase was quenched with glacial acetic acid $20 \%$ for $2 \mathrm{~min}$ at $4{ }^{\circ} \mathrm{C}$. Sections were treated for $1 \mathrm{~h}$ at room temperature with UEA-I lectin (Vector Laboratories, Burlingame, CA) at a concentration of $0.8 \mu \mathrm{g} / \mathrm{ml}$ in phosphate buffered saline (PBS, $\mathrm{pH}$ 7.2). The sections were washed three times with PBS. The sections were then immersed in labeled streptavidinbiotin (LSAB) plus alkaline phosphatase (AP) link universal (Dako Corporation, Carpinteria, CA) and incubated for $15 \mathrm{~min}$ at room temperature. Sections were then equilibrated with Tris-buffer ( $\mathrm{pH}$ 9.5) for $5 \mathrm{~min}$ at room temperature. The final reaction was produced by immersing the sections in a solution of red substrate (Vector ${ }^{\circ}$ Red Alkaline Phosphatase Substrate, Vector Laboratories) for $20 \mathrm{~min}$ at room temperature. The sections were lightly counterstained with Mayer's haematoxylin, dehydrated 
through graded concentrations of ethanol and xylene, and mounted. Lectin binding specificity was tested with the following: (i) mixing the lectin with a $0.1 \mathrm{M}$ solution of its inhibitory sugar (L-fucose) for $20 \mathrm{~min}$ before performance of lectin histochemistry; and (ii) treating sections with $1 \%$ sodium periodate prior to labeling for $10 \mathrm{~min}$. Both pretreatments prevented staining. The small intestine tissues from Escherichia coli-infected pigs were used as positive control for lectin histochemistry of UEA-I [16]. The porcine ileal Peyer's patches tissues were used as negative control for lectin histochemistry of UEA-I [17].

\section{Morphometric analysis}

For the morphometric analyses of in situ hybridization and lectin histochemistry, 3 sections were cut from each of three blocks of tissue from lung of each pig. The slides were analyzed using the NIH Image J $1.43 \mathrm{~m}$ program (http://image.nih.gov/ij/download.html) to obtain the quantitative data. For the analysis of $M$. hyopneumoniae in situ hybridization, 10 fields were randomly selected and slides were scored ranging from 0 (no signal detectable) to 3 (intense labeling on the surface of bronchial and bronchiolar epithelium) as previously described [18]. For the analysis of UEA-I histochemistry, 10 fields were randomly selected and slides were scored ranging from 0 (no signal detectable) to 3 (intense labeling on the surface of bronchial and bronchiolar epithelium).

\section{Radiolabeling of bacteria}

Eight $P$. multocida type A isolates from porcine enzootic pneumonia were used for radiolabeling. Radioiodination of $P$. multocida type A was carried out as described previously [8] with slight modification. Bacteria $\left(0.5 \mathrm{ml} ; 10^{8}-10^{9}\right.$ cells in $0.3 \mathrm{M}$ sodium phosphate buffer, $\mathrm{pH}$ 6.8) were transferred to $10 \times 75 \mathrm{~mm}$ tubes previously coated with $100 \mu \mathrm{g}$ of Iodogen (Sigma Chemical Company, St. Louis, MO), and reacted with 1 $\mathrm{mCi}$ of $\mathrm{Na}^{125}$ I (Perkin-Elmer, Boston, MA) at $4{ }^{\circ} \mathrm{C}$ for $10 \mathrm{~min}$ followed by a $5 \mathrm{~min}$ incubation at room temperature. Iodination was terminated by removing the cells followed by centrifugation, followed by three washes with $0.05 \mathrm{M}$ Tris $-\mathrm{HCl}(\mathrm{pH}$ 7.8) containing 0.15 $\mathrm{M} \mathrm{NaCl}$ and $1 \%$ bovine serum albumin (TBS-BSA). The labeled bacteria were resuspended at a cell density of $5 \times 10^{7}-10^{8}$ cells per $\mathrm{ml}$ in TBS-BSA.

\section{Bacterial overlay assay}

P. multocida type A binding to L-fucose (Sigma Chemical Company) was tested as previously described with slight modification [19]. L-fucose $(0,0.5,1,2$, and $5 \mu \mathrm{g})$ was spotted on aluminum-backed silica gel high-performance plates (Merck, Germany). Plates were dried, dipped in hexane containing $0.1 \%$ polyisobutylmethacrylate, and air- dried. The plates were sprayed with TBS-BSA and immersed in TBS-BSA for $1 \mathrm{~h}$. After excess buffer was drained from the plates, they were overlaid for $4 \mathrm{~h}$ with $60 \mu \mathrm{l}$ of ${ }^{125}$ I-labeled bacteria (approximately $1 \times 10^{6}$ colony forming units $/ \mathrm{ml}$ ) in TBS-BSA. Plates were washed five times with PBS to remove unbound bacteria, dried, and exposed overnight to X-ray film (Eastman Kodak, Rochester, NY) at room temperature.

\section{Statistical analysis}

Spearman's correlation was used to assess the relationship between in situ hybridization (M. hyopneumoniae) and lectin histochemistry (UEA-I). A value of $P<0.05$ was considered significant.

\section{Results}

In situ hybridization of $M$. hyopneumoniae

The morphology of host cells was preserved despite the relatively high temperatures and chemical treatments required in the procedure. A very close cell-to-cell correlation among serial sections from each lung sample was confirmed by in situ hybridization. The signal intensity varied within and between histological, bronchi and bronchioles, in sections of a single animal and also between pigs. Positive cells typically exhibited a dark brown reaction protduct without background staining. $M$. hyopneumoniae DNA was detected at the luminal surface of bronchial and bronchiolar epithelial cells (Fig. 1a), alveolar (Fig. 2a) and interstitial macrophages, and type I pneumocytes (Fig. 2b) in the lung from all infected pigs at $7,14,21$, and 28 dpi. A positive hybridization signal was especially intense at the luminal surface of bronchial and bronchiolar epithelial cells, whereas the hybridization was sparse in alveolar and interstitial macrophages, and type I pneumocytes. When a hybridization signal was detected at the luminal surface of bronchial and bronchiolar lining epithelial cells, a given bronchus or bronchiole also exhibited peribronchiolar lymphoid cuffing. Pretreatment with DNase I eliminated the hybridization signal from 16 pigs experimentally infected with $M$. hyopneumoniae and from positive control pigs. Sections from negative control pigs showed no hybridization signals for $M$. hyopneumoniae (Fig. 1c).

\section{Lectin histochemistry for L-fucose residues}

A very close cell-to-cell correlation among serial sections from each lung sample was confirmed by lectin histochemistry. In M. hyopneumoniae-infected lungs, UEA-I stained the luminal surface and cytoplasm of bronchial and bronchiolar epithelial cells in the lung from all infected pigs at 7, 14, 21, and 28 dpi. Positive cells typically exhibited a red reaction product without background staining. The luminal surface and cytoplasm of bronchial 


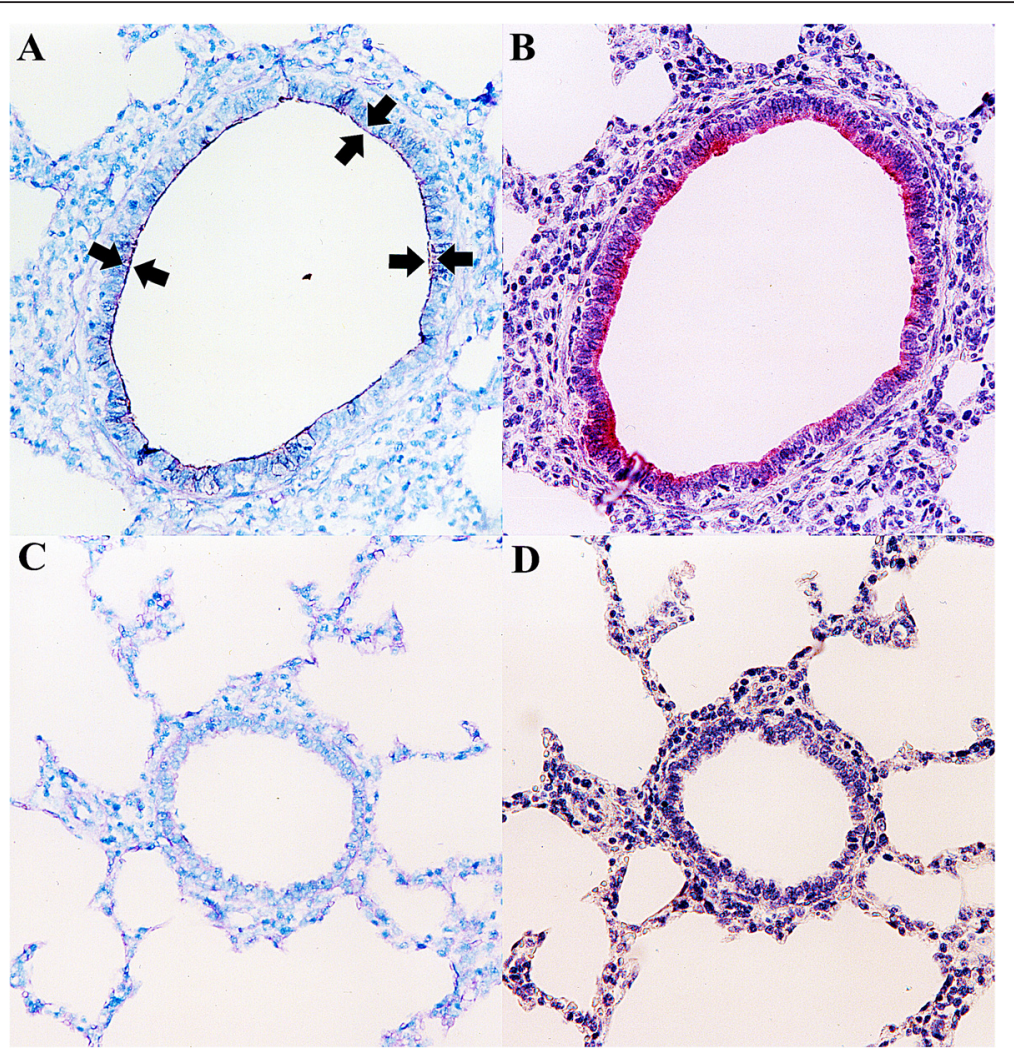

Fig. 1 In situ hybridization and lectin histochemistry. Serial sections of the Mycoplasma hyopneumoniae-infected pigs at 21 dpi show that the majority of areas containing strong M. hyopneumoniae DNA signals (dark brown reaction, arrows; a) also have numerous UEA-I staining (red reaction; b) in the bronchial and bronchiolar epithelial cells. Serial section of the lung tissue from negative control pigs show negative M. hyopneumoniae DNA (c) and UEA-I staining (d) signals

and bronchiolar epithelial cells stained strongly with UEA-I in lungs from infected pigs at 14 and $21 \mathrm{dpi}$ (Fig. 1b). No UEA-I staining was seen at the luminal surface or in the entire cytoplasm of bronchial and bronchiolar epithelial cells of negative control pigs (Fig. 1d). Pretreatment with L-fucose and sodium periodate eliminated histochemical staining by UEA-I in 16 pigs experimentally infected with $M$. hyopneumoniae and in positive control pigs.

\section{Correlation between M. hyopneumoniae and L-fucose residues}

There was close cell-to-cell correlation when serial sections were examined by in situ hybridization with $M$. hyopneumoniae and lectin histochemistry with UEA-I in lung from infected pigs at 7, 14, 21, and $28 \mathrm{dpi}$. Colocalization of $M$. hyopneumoniae (Fig. 1a) and UEA-I (Fig. 1b) was especially prominent in the luminal surface of bronchial and bronchiolar epithelial cells. The luminal surface of bronchial and bronchiolar epithelial cells stained with UEA-I (Fig. 1c) always showed hybridization signals for M. hyopneumoniae (Fig. 1d) but it was negative in the unaffected parts of the lung from M. hyopneumoniae-infected pigs and in lung from negative control pigs. The score for the mean number of $M$. hyopneumoniae-positive cells per unit area of lung was correlated with the score for the mean number of UEA-I-positive cells per unit are of lung at $7(r=0.202$ and $P=0.027), 14(r=0.522$ and $P=0.001), 21 \quad(r=0.259$ and $P=0.004)$, and $28(r=0.304$ and $P=0.001) \mathrm{dpi}$.

\section{Bacterial overlay assay}

Eight $P$. multocida type A isolates were analyzed for their ability to bind L-fucose using bacterial overlay assay. As shown by autoradiogram, none of eight $P$. multocida type A bound to L-fucose at a level of $0.5 \mu \mathrm{g}$. Two P. multocida type A did not bind to L-fucose at a level of $1 \mu \mathrm{g}$ whereas the remaining six $P$. multocida type A bound faintly. All eight $P$. multocida type A bound strongly at levels of $2 \mu \mathrm{g}$ and $5 \mu \mathrm{g}$ of L-fucose (Fig. 3). No binding was observed in negative controls.

\section{Discussion}

The results of the present study demonstrate that increased the L-fucosyl composition in M. hyopneumoniae-infected pigs enhance adherence of $P$. multocida 


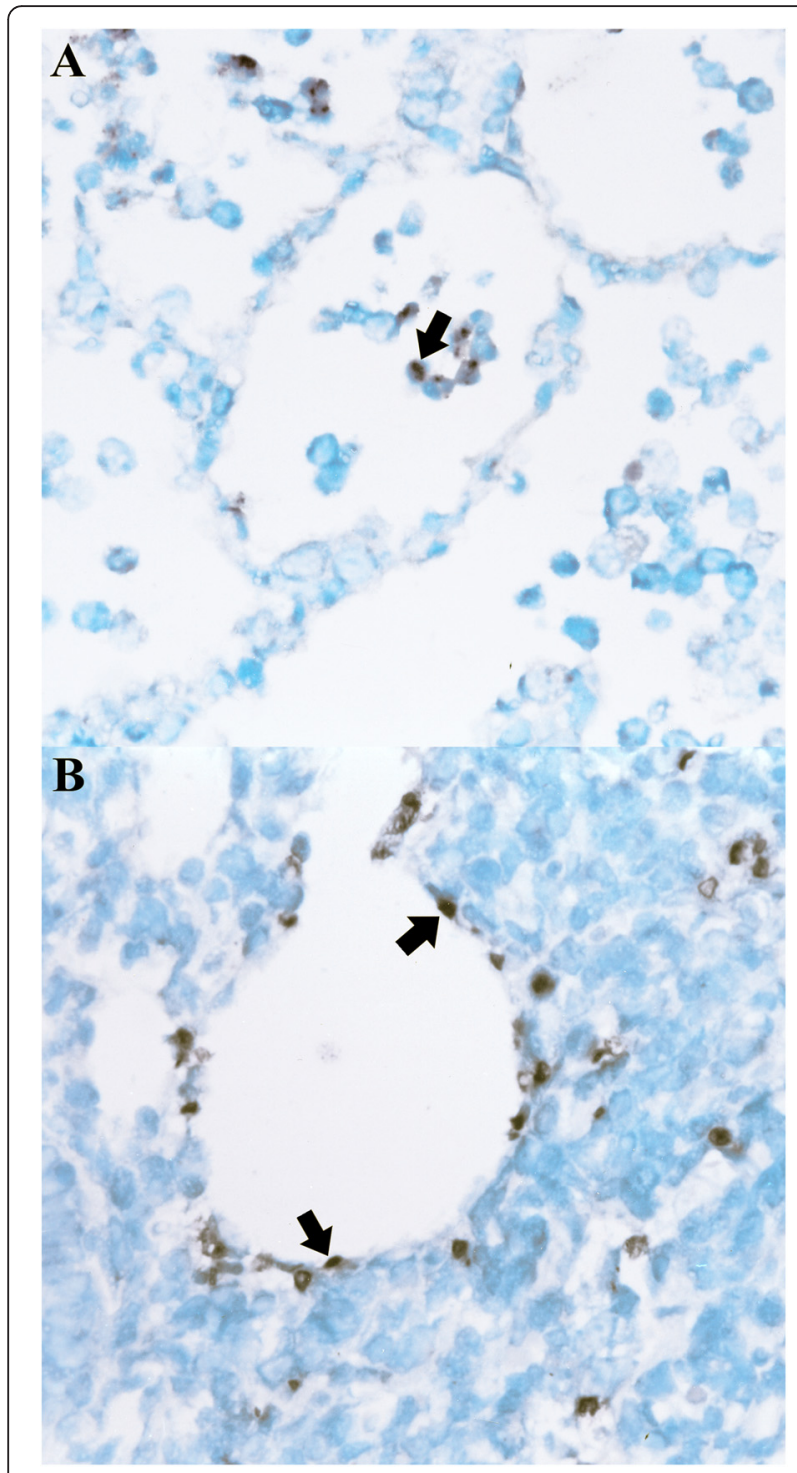

Fig. 2 In situ hybridization. Mycoplasma hyopneumoniae DNA signals (dark brown reaction) are detected in alveolar macrophages (arrow, a) and type 1 pneumocytes (arrows, b) from M. hyopneumoniae-infected pigs at $21 \mathrm{dpi}$

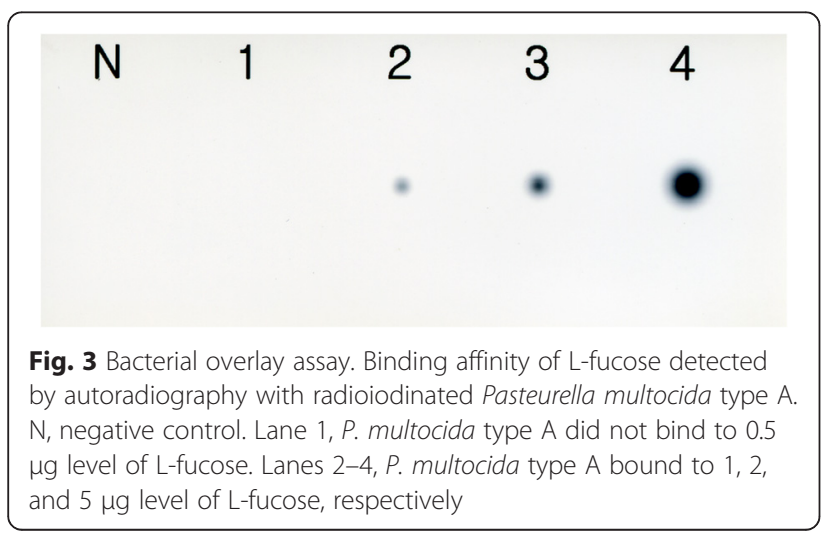

type A in the bronchial and bronchiolar epithelial cells. The numbers of $M$. hyopneumoniae-positive cells is correlated with the numbers of UEA-I-positive cells in infected cells. UEA-I staining could also be influenced by mycoplasmal enzymes; however, $M$. hyopneumoniae lack the enzyme fucosidase [20]. Therefore, UEA-I staining of the luminal surface and cytoplasm of bronchial and bronchiolar epithelial cells indicates that L-fucose may be a terminal residue on glycoconjugates synthesized by these cells in $M$. hyopneumoniae-infected pigs. In addition, eight $P$. multocida type A isolated from porcine enzootic pneumonia also showed strong affinity for L-fucose by bacterial overlay assay. A bacterial overlay assay was used to evaluate the binding of respiratory pathogens to glycoconjugates or glycolipids $[8,19]$. These results suggest that increased expression of Lfucose containing glycoconjugates induced by $M$. hyopneumoniae infection may provide greater numbers of binding sites for P. multocida type A and subsequent infection with $P$. multocida type A results in severe enzootic pneumonia.

Increased fucosyl glycoconjugate in $M$. hyopneumoniae-infected pigs is potential factor to enhance colonization of P. multocida type A in bronchial and bronchiolar epithelial cells. Alternatively, M. hyopneumoniae colonizes the ciliated epithelial cells of the respiratory tract and damages the cells which lead to an enhanced infection of $P$. multocida type A [2]. A strong hybridization signal of $M$. hyopneumoniae was detected mainly in the luminal surface of bronchial and bronchiolar lining epithelial cells. Our results are consistent with an ultrastructural study, in which $M$. hyopneumoniae attaches to the cilia in the bronchial and bronchiolar epithelial cells [21, 22]. These results suggest that $M$. hyopneumoniae is intimately associated with the cilia and causes extensive loss of these structures. M. hyopneumoniae causes ciliostasis and damages to the ciliated epithelial cells of the respiratory tract $[1,21,22]$, rendering the lungs susceptible to $P$. multocida type A colonization and infection.

This study explains how M. hyopneumoniae enhance the secondary infection of $P$. multocida type A leading to enzootic pneumonia. Altered composition of glycoconjugates as the result of mycoplasma infection may be one factor that predisposes pigs to enhance $P$. multocida type A infection in the lung. However, co-infection with $M$. hyopneumoniae and P. multocida type A was not conducted in this study. Therefore, further studies are needed to confirm enhanced adherence of $P$. multocida type A to ciliated epithelial cells of the respiratory tract using animal model with co-infection. Altered composition of glycoconjugates by $M$. hyopneumoniae, together with damaging to ciliated epithelial cells of the respiratory cells, generates a favorable environment promoting 
colonization and secondary infection of $P$. multocida type A resulting in porcine enzootic pneumonia.

\section{Conclusions}

The objective of this study is to elucidate the pathogenic mechanisms of how M. hyopneumoniae enhances secondary P. multocida type A infection which leads to porcine enzootic pneumonia in infected pigs. Altered composition of glycoconjugates by $M$. hyopneumoniae, together with damaging to ciliated epithelial cells of the respiratory cells, generates a favorable environment promoting colonization and secondary infection of $P$. multocida type A resulting in porcine enzootic pneumonia.

\section{Competing interests}

The authors declare that they have no competing interests.

\section{Authors' contributions}

Performance of the study: CP, JJ. Analysis and interpretation of data: IK, KC, S-J P. Study conception and design: CC. All authors read and approved the final manuscript.

\section{Acknowledgements}

The author's research was supported by Technology Development Program for Agriculture and Forestry from Ministry of Agriculture, Food and Rural Affairs, Republic of Korea. This research was also supported by contract research funds of the Research Institute for Veterinary Science from the College of Veterinary Medicine and by Brain Korea Plus 21 Program for Creative Veterinary Science Research in the Republic of Korea.

Received: 10 September 2015 Accepted: 28 January 2016

Published online: 03 February 2016

References

1. Maes D, Verdonck M, Deluyker H, de Kruif A. Enzootic pneumonia in pigs. Vet Quart. 1996;18:104-9.

2. Thacker EL, Christopher Minion C. Mycoplasmosis. In: Zimmerman JJ, Karriker LA, Ramirez A, Schwartz KJ, Stevenson GW, editors. Diseases of Swine. 10th ed. Ames: Wiley-Blackwell Publishing; 2012. p. 779-97.

3. Hall WF, Bane DP, Kilroy CR, Essex-Sorlie DL. A model for the induction of Pasteurella multocida type-A pneumonia in pigs. Can J Vet Res. 1990;54:238-43.

4. Amass SF, Clark LK, Van Alstine WG, Bowersock TL, Murphy DA, Knox KE, et al. Interaction of Mycoplasma hyopneumoniae and Pasteurella multocida infections in swine. J Am Vet Med Assoc. 1994:204(1):102-7.

5. Choi C, Kim B, Cho W-S, Kim J, Kwon D, Cheon D-S, et al. Capsular serotype, toxA gene, and antimicrobial susceptibility profiles of Pasteurella multocida isolated from pigs with pneumonia in Korea. Vet Rec. 2001;149:210-2.

6. Bavington C, Page C. Stopping bacterial adhesions: a novel approach to treating infection. Respiration. 2005:72:335-44.

7. Beachey EH. Adhesin-receptor interactions mediating the attachment of bacteria to mucosal surfaces. J Infect Dis. 1981:143:325-45.

8. Krivan HC, Roberts DD, Ginsburg V. Many pulmonary pathogenic bacteria bind specifically to the carbohydrate sequence GalNAcß1-4Gal found in some glycolipids. Proc Natl Acad Sci U S A. 1988;85:6157-61.

9. de Bentzmann S, Roger P, Dupuit F, Bajolet-Laudinat O, Fuchey C, Plotkowsk MC, et al. Asialo GM1 is a receptor for Pseudomonas aeruginosa adherence to regenerating respiratory epithelial cells. Infect Immun. 1996;64:1582-8.

10. Ackermann MR, Debey MC, Debey BM. Bronchiolar metaplasia and Ulex europaeus agglutinin I (UEA-I) affinity in Mycoplasma hyopneumoniaeinfected lungs of six pigs. Vet Pathol. 1991;28:533-5.

11. Kim D, Kim CH, Han K, Seo HW, Oh Y, Park C, et al. Comparative efficacy of commercial Mycoplasma hyopneumoniae and porcine circovirus 2 (PCV2) vaccines in pigs experimentally infected with $M$. hyopneumoniae and PCV2. Vaccine. 2011:29:3206-12.

12. Vena MM, Blanchard B, Thomas D, Kobisch M. Adherence of Pasteurella multocida isolated from pigs and relationship with capsular type and dermonecrotic toxin production. Ann Vet Res. 1991;22:211-8.
13. Harasawa R, Koshimizu K, Takeda O, Uemori T, Asada K, Kato I. Detection of Mycoplasma hyopneumoniae DNA by the polymerase chain reaction. Mol Cell Probe. 1991;5:103-9.

14. Kwon D, Chae C. Detection and localization of Mycoplasma hyopneumoniae DNA in lungs from naturally infected pigs by in situ hybridization using a digoxigenin-labeled probe. Vet Pathol. 1999;36:308-13.

15. Kwon D, Choi C, Chae C. Chronologic localization of Mycoplasma hyopneumoniae in experimentally infected pigs. Vet Pathol. 2002;39:584-7.

16. Sohn Y-S, Chae C. Lectin-binding capacity of glycoconjugates in Escherichia coli O9:K103:NM, 987 $\mathrm{P}^{+} \mathrm{ST}^{+}$-infected porcine lower small intestines. J Vet Med Sci. 2000:62:543-7.

17. Jeong K-I, Sohn Y-S, Ahn K, Choi C, Han DU, Chae C. Lectin histochemistry of Peyer's patches in the porcine ileum. J Vet Med Sci. 2002;64:535-8.

18. Opriessnig T, Thacker EL, Yu S, Fenaux M, Meng X-J, Halbur PG. Experimental reproduction of postweaning multisystemic wasting syndrome in pigs by dual infection with Mycoplasma hyopneumoniae and porcine circovirus type 2. Vet Pathol. 2004;41:624-40.

19. Hansson GC, Karlsson K-A, Larson G, Stromberg N, Thurin J. Carbohydratespecific adhesion of bacteria to thin-lay chromatograms: A rationalized approach to the study of host cell glycolipid receptors. Anal Biochem. 1985; 146:158-63.

20. Kies LM, DeBey MC, Ross RF. Identification of porcine mycoplasmas using commercial enzyme assay systems. J Vet Diagn Invest. 1991;3:348-50.

21. Blanchard B, Vena MM, Cavalier A, Lannic JL, Gouranton J, Kobisch M. Electron microscopic observation of the respiratory tract of SPF piglets inoculated with Mycoplasma hyopneumoniae. Vet Microbiol. 1992;30:329-41.

22. Mebus CA, Underdahl NR. Scanning electron microscopy of trachea and bronchi from gnotobiotic pigs inoculated with Mycoplasma hyopneumoniae. Am J Vet Res. 1977;38:1249-54.
Submit your next manuscript to BioMed Central and we will help you at every step:

- We accept pre-submission inquiries

- Our selector tool helps you to find the most relevant journal

- We provide round the clock customer support

- Convenient online submission

- Thorough peer review

- Inclusion in PubMed and all major indexing services

- Maximum visibility for your research

Submit your manuscript at www.biomedcentral.com/submit
Biomed Central 